\title{
A study on attitude towards ageing among the older persons
}

\author{
K.Maheswari $^{1}$ and R.Maheswari ${ }^{2}$ \\ ${ }^{1}$ Assistant Prof, Department of Social Work, Bharathidasan University Constituent College, \\ Perambalur, Tamil Nadu, India. \\ ${ }^{2}$ Research Scholar, Dept of Social Work, Bharathidasan University Constituent College, \\ Perambalur, Tamilnadu, India.
}

\begin{abstract}
Aging has become an issue of global concern and due to demographic and socio-cultural changes aging is not only a concern at a personal level but also at national levels. Developed countries are already experiencing the consequences of population ageing and the older persons in India have to face the positive as well as the negative aspects of ageing due to various factors. Attitude is a psychological tendency to evaluate a particular entity with some degree of favour or disfavour (Eagly,1993). The attitude will have a strong influence on individual's behaviour and it helps to communicate with one's feelings. Hence, the present study is an empirical attempt to understand the attitude towards ageing among the older persons residing in Perambalur district. Descriptive research design was used and simple random sampling method was adopted to select a sample of 100 respondents (50 rural and 50 urban) from the voters list. Self prepared interview schedule method was used to collect the socio demographic data from the respondents and a standardized tool on attitude towards ageing was applied. The major findings of the study revealed that nearly half of the respondents have moderate level of physical changes $(45 \%)$ and psychological growth $(43 \%)$ and high level of psychological loss (48\%) and had moderate attitude towards ageing. Male respondents had high attitude towards ageing compared with female older persons.
\end{abstract}

Key words: Attitude, ageing, psychological loss, physical changes.

\section{Introduction}

Old age is an important period in the development stage of a human being and the older persons become more vulnerable and are prone to develop physical and psychological ailments. Researchers must have better understandings of the older persons especially in recent years because majority of the older persons are physically and psychologically healthy up to the age of 70 years and they are working even after 60 years and are reducing the economic burden and dependency. An attitude is "a relatively enduring organization of belief's, feelings and behavioural tendencies towards socially significant objects, groups, events or symbols (Hogg and Vanghan, 2005). When a person expresses socially acceptable attitudes, they will be rewarded and approved for their behaviour. Positive attitude helps a person to mediate between their own inner needs and the outside world. Older persons with positive beliefs about their ageing are less likely to develop functional disabilities.

Age is just a number if a senior citizen sees the life positively and it will lead to successful ageing. Generally, people assume that people at old age suffer from diseases, mental illness, accident prone etc but there is no evidence that a healthy person's intellectual ability decreases with age and they cannot lead an active life as age increases. But when the older persons are inquired about their old age and their health conditions, they have a strong belief that they are not aged and they are physically and psychologically healthy. The gap between reality and the ideal life of older person is really larger and lot of difference is seen in the ageing process of the aged. The contribution of older persons to their families and communities cannot be quantified. It is also evident that older persons are motivated to maintain their economic conditions, health status, and activity levels, adjust to geographical locations, life style, food habits and spiritual life etc. As age increases the physical, psychological loss and psychological growth of older people changes and it forms the important criteria to evaluate the quality of life of the elderly.

Several studies have been investigated on attitude towards ageing among the older persons and 
others opinion ageing process had also been conducted. Griffin(2016) has revealed the attitude to aging can have a direct effect on health. Negative attitudes to ageing will affect both physical and cognitive health in later years, and the study done by the Irish Longitudinal Study on Ageing (TILDA), at Trinity College Dublin, further revealed that participants with positive attitudes had improved cognitive ability in old age. Older adults with negative attitudes had slower walking speed, and worse cognitive abilities. It was also revealed those participants' medications, mood, their life circumstances and other health changes had improvement when they had positive attitude towards ageing.

One of the studies has showed more negative ratings in attitudes to ageing and quality of life among the over 80 year old age group. Somkiat (2018) conducted a study among the Bangkok population aged 18-59 years in terms of their attitude toward the elderly and social interaction. The survey data of the lifestyle and values of the respondents had been analyzed using two-step cluster analysis. The 1,020 respondents were classified into seven main clusters and 16 sub-groups based on their lifestyle and values. Positive attitude towards ageing has an impact on social interaction pattern and fills the intergenerational gap. Policies for improving attitude toward the elderly and social interaction enhancement for each sub-group were suggested to promote a harmonious intergenerational society.

Low (2013) found that attitudes mediate the relationship between health satisfaction and quality of life. It was from the secondary analysis of crosssectional survey data collected in 20 countries in 2003. The study sample consisted of 4593 respondents on average, 72.10 years of age and 42.8 per cent were female. Attitude towards ageing and quality of life were studied and the major findings were that attitudes toward physical change were the strongest mediator of health satisfaction upon global and domain-specific quality of life, followed by psychosocial loss and psychosocial growth.

\section{Aim}

The aim of the study is to assess the attitude towards ageing among the older persons residing in Perambalur district.

\section{Objectives of the study}

1.) To understand the background characteristics of the respondents.

2.) To find out the attitude of older persons towards ageing.

3.) Estimation of association between the selected socio demographic variables and dimensions of attitude towards ageing.

\section{Methodology}

In this study, the researcher has taken effort to investigate the attitude of older persons towards ageing and has described the characteristics of the respondents along with three dimensions physical change, psychological loss and psychological growth. The Universe of the study comprised of all the older persons residing in rural and urban areas of Perambalur District. Tamilnadu. The researcher has selected 100 respondents (50 rural and 50 urban) using simple random sampling method from the voters list and the sample size is 100 . The researcher has used self prepared interview schedule to collect the socio demographic information's and a standardized tool on attitude towards ageing developed by Laidlaw et al, in 2007 was used to measure the attitude on ageing and it has three dimensions such as physical change, psychological loss and psychological growth. The scale consists of 24 items. Using Statistical Package for Social Sciences (SPSS) analysis was done and various tests were applied to find the association and difference between variables.

\section{Results and Discussions}

Social Profile: The major findings of the study have been explained in detail and the age distribution of the older persons showed that less than half of the respondents (46\%) are in the group of 60 to 69 years whereas 35 per cent comes under 70 to 79 years of age and only 19.9 per cent of the respondents are above 80 years. Majority of the respondents $(76 \%)$ are female and 24 per cent are male. Regarding marital status, 37 per cent are married and living with spouse and more than half of the respondents $(57 \%)$ are in widowhood, 4 per cent of them are alone and 2 per cent of the respondents are unmarried. Educational qualification of the subjects showed that 20 per cent of the respondents have studied up to primary level, few respondents $(11 \%)$ have studied up to middle school, only 3 per cent of them attended up to secondary class and majority of the respondents $(66 \%)$ are illiterate. Majority of the respondents $(77 \%)$ are Hindus whereas 18 per cent of them are Christians and rest are Muslims.

Living arrangements: Living arrangement is an important term in understanding the support system for elderly and it explains the well- being of the older persons. While analysing the living arrangements, 46 per cent of the respondents are living with children and spouse whereas 47 per cent of them are residing with children and grandchildren and 4 per cent of them are alone and 3 percent with others. Equal number of the respondents $(50 \%)$ hail from rural and urban areas. 
Economic status: While considering the economic status of the respondents, nearly half of the respondents (49\%) have an income below Rs.2000 and 48 per cent of the respondents monthly income is between Rs.2001 to Rs.12,000 and few per cent of the respondents(3\%) monthly income is above 12,000 . Regarding the present occupational status, 21 per cent of the respondents are pensioner's whereas 34 per cent of them are doing agriculture and homemakers, and 29 per cent of the respondents have possessed other jobs like maids, daily wagers, petty shop and business. Ownership of property decides a person's social status and decision making authority and regarding assets of the respondents, few members (6\%) possess movable property, whereas little more than half of the respondents (53\%) possess immovable property and 39 per cent of the respondents do not have any property.

Health status: Health status is an important indicator of well-being and also it predicts the attitude of the elderly towards ageing process. The presence of diseases and functional disability is unavoidable during old age and it is seen from the analyzes that, 11 per cent of the respondents health status was worse and had one or more acute or chronic diseases, whereas 29 per cent of the respondents current health status was poor, and 42 per cent of them had better health condition and 18 per cent of them were healthy.

Attitude towards ageing: It is observed from the study that, nearly half of the respondents (48\%) have higher level of psychological loss and little less than half of the respondents have moderate level of physical change $(45 \%)$ and psychological growth $(43 \%)$. However from the overall score it is clear that, 35 per cent of the respondents have high attitude towards ageing. Nowadays older persons are active, self reliant, onset of functional disability is delayed and if they are able to maintain their health condition, they are able to cope with physical and psychological deterioration.

Results of various tests indicate that, there is a high significant association between the age of the respondents with regard to various dimensions of attitude towards ageing such as psychological loss, psychological growth, physical change and overall score. From the mean score, it is understood that 7079 years people have low attitude towards ageing than other groups and it may be because of their physical ailments, dependency and functional disability and as age increases there is decrease in the psychological growth. There is a high significant difference between the gender and various dimensions of attitude towards ageing such as psychological growth and overall score and there is a significant difference between the genders of the respondents with regard to psychological loss dimension. From the mean value, male respondents show high level of attitude towards ageing compared with female older persons. There is no significant difference between the domicile of the respondents and attitude towards ageing. From the mean value it was clear that, respondents from urban areas show high level of attitude towards ageing compared with respondents from rural area.

There is a high significant association between the numbers of dependents and physical change dimension because most of the elderly give their earnings to the family and some of them take full responsibility of their family expenses. There is no significant association between family size, property, number of children and attitude towards ageing. Regarding health status, there is a high significant association between the present health statuses of the respondents and physical change, psychological loss, psychological growth dimensions and overall score. Health decides one's life span and well being of the elderly and hence health must be given utmost importance to lead a safe and positive ageing. There is a significant difference among the marital status and physical change of the respondents and it is clear that most of the aged are in widowhood after 70 years and the loss of spouse affects their attitude and health of the older persons. From the study, it is evident that the respondents have moderate level of attitude towards ageing and young old have better understanding about old age because they are able to see the changes in ageing process and its coping mechanisms and they are planning to lead active life.

\section{Conclusion}

Positive ageing is understood as a development of positive attitude, feeling good about self, keeping fit and healthy, and active engagement throughout the life. Every older person must maintain a positive attitude towards ageing and the positive attitude will delay the aging process. From the various researches, it is evident that negative attitude on ageing may deteriorate the well-being and there will be early onset of functional disability". A positive attitude towards ageing will help to develop more resilience, despite the challenges that associated with growing older. Thus, every individual must be active and stay fit with good diet, exercise and habits throughout the life span.

\section{References}

[1] Eagly and Chaiken, The Psychology of Attitudes, I Edn. Vol.1, Fort Worth, Tex: Harcourt Brace Jovanovich College Publishers.pp- 794, (1993).

[2] Vaughan and Hogg, Introduction to Social Psychology ( $4^{\text {th }}$ Edition). Frenchs Forest, N.S.W : Pearson Education. Pp: 1-440, (2005). 
[3] Griffin, Attitude to Aging can have a direct effect on Health. Science Daily, Medical press. Trinity College, Dublin, (2016.)

[4] Eiamkanchanalai, Assarut and Surasiengsunk, Attitude towards the elderly and social interaction: Approach toward an intergenerational

\section{ISSN 2455-6378}

society. Kasetsart Journal of Social Sciences. Elsevier. Vol.39, (Issue. 3). (2018).

[5] Low, Molzahn and Schopflocher, Attitudes to aging mediate the relationship between older peoples' subjective health and quality of life in 20 countries. Health Qual Life Outcomes. BioMed Central the open access publisher. Vol.11, pp 146, (2013). 